\title{
A Procedure of How to Conduct Research in Transparent Mobile Recommendations
}

\author{
Mike Radmacher \\ Chair of Mobile Business \& Multilateral Security, \\ Gräfstr.78, 60054 Frankfurt am Main, Germany, \\ mike.radmacher@m-chair.net
}

\begin{abstract}
The information overflow of today's information society can be overcome by the usage of recommender systems. Due to the fact that most recommender systems act as black boxes, trust in a system decrease, especially when a recommendation failed. Recommender systems usually don't offer any insight into the systems logic and cannot be questioned as it is normal for a recommendation process between humans. Transparency, which is about explaining to the user why a recommendation is made, supports the user in a way of understanding the reasoning behind a recommendation. Within a mobile environment, it is possible to address the user more individualized but transparency needs a completely different way of visualization and interaction. The paper in hand aims at setting up a process model on how to address transparency in mobile recommendations and therefore introduce into a complex new area of research, recommender systems didn't address in the past.
\end{abstract}

\section{Introduction}

Today's information society which includes the emergence of the information flow, confronts the user with the conflict between getting the information he is looking for and spending the time he is able to, while searching for what he is interested in $[1,2]$. "To give customers exactly what they want, you first have to learn what that is. It sounds simple, but it's not" [3]. At this time, recommender systems

Please use the following format when citing this chapter:

Radmacher, M., 2008, in IFIP International Federation for Information Processing, Volume 286, Towards Sustainable Society on Ubiquitous Networks, eds. Oya, M., Uda, R., Yasunobu, C., (Boston: Springer), pp. 49-60. 
gain significant importance by supporting the user to find what he is actually looking for. Sometimes this also means to support the service provider for "suggesting ... those products which best suit his needs and preferences in a particular situation and context" [4].

Recommender systems are well known in the academia as well as in practice over the last 20 years. GroupLense [5], MovieLense [6], Video Recommender [7], Ringo [8] and Fab [9] are only a few systems that are developed by researchers. Some websites like Amazon.com, CDNow.com, Barnes \& Nobel, MovieFinder.com, Pandora.com, TiVo.com, Netlix.com or Launch.com have also made successful use of recommender systems [11].

But when we talk about transparency as the explanation why a particularly recommendation is made, most of the recommender systems act as black boxes [12]. They cannot be questioned [11] and the systems logic behind the recommendation isn't visible. Trust in a recommender system decreases if the recommendation failed without any reasons. Transparency which can explain how the system works $[13,14,15]$, enables the user to make a more accurate judgment of the true quality of a recommended item [16]. In a mobile environment, transparency is even more important due to the processing of personal information e.g. location data, time of usage, interests, and other situational dependent information that can be used to offer a more individualized recommendation [17,18]. Processing this information, especially location data, needs mostly users' approval [19, 20].

The paper in hand sets up a procedure on how to address transparency in mobile recommendations and therefore introduce a complex new area of research, recommender systems didn't address in the past.

The paper is structured as follows: The section "Theoretical Framework" gives an overview about transparency in the area of recommender systems and demonstrates its importance as well as its novelty. The section "Research Methodology" discusses the underlying research approach, related to design research, research questions, artifacts as well as the created procedure on how to investigate transparency in mobile recommendations. The four following sections are describing each phase of the procedure, while the last section sums up the contribution of what is learned and how further questions can be addressed in more detail.

\section{Theoretical Framework}

Research in the area of recommender systems is performed over the last 20 years in a few different areas. The algorithm refinement, the analysis of user behavior and the consideration of user feedback are typically distinguished.

Algorithm refinement is conducted on the one hand by optimizing recommender techniques like rule-based filtering, content-based filtering, collaborative filtering and hybrid approaches $[9,21,22,23,24]$ and on the other hand by addressing new application areas with specific domain related input vector e.g. music [25] or video [5.6]. The analysis of user behavior is accomplished by classical research separated into the active way which asks the user explicitly about his behavior [26] and the passive way [27,28] where the behavior is derived by indirectly information 
collection and interpretation. The third path of research in recommender systems addresses the consideration of user feedback, often given by the buzzword "recommendation by critique" [4,29].

All these topics are of importance but for a while it has recognized that a new aspect called transparency also plays an important role of the acceptance and usage of recommender systems.

Using recommender systems means, users typically disclose some personal opinions e.g. in the form of ratings. Based on these ratings, a recommendation e.g. for movies, books other products is made. The user has the possibility to accept or reject the recommendation. Over the years literature indicated that recommender systems are not always be trusted by users $[11,12,21]$. Most of the recommender systems act as black boxes, not offering any insight into the systems logic or justifications for recommendations and cannot be questioned [11,12,22]. Recommendations are often correct, but also occasionally very wrong [11]. There are no indicators given when trusting a recommendation and when to doubt one from a user's point of view [11]. In addition a user is very sensible when it comes to recommendations in an area he is not familiar with [12]. But when a user doesn't trust a recommender system, he will not disclose personal information.

By offering transparency which is about explaining to the user why a recommendation is made, the user will trust a service provider more than before $[10,12,30]$. In case something went wrong, the level of trust normally decreases, but when transparency is offered to understand what happened, trust does not have to decrease. Transparency explains how a system works [30], enables more accurate judgment of the quality of a recommended item [13]. It offers a higher acceptance of recommendations and can increase sales [12]. The user can question the recommendation which also helps the system to refine the recommendation process [11]. Transparency is even more important in a mobile environment because personal information e.g. location data, time of usage, interests, and other situational dependent information can be used to offer a more individualized recommendation $[17,18]$. Its processing needs mostly users' approval $[19,20]$. Transparency provides a method to check if personal privacy policies are respected. Furthermore, in a mobile environment, transparency also needs a completely different way of visualization and interaction [31].

The aim of this contribution is to offer a guideline on conducting research in the area of transparent mobile recommendations - a reference procedure that allows designing transparent mobile recommendations as well as its integration into classical recommender processes, which includes the refinement of recommender processes by user feedback, collected through the questioning of transparent recommendations.

\section{Research Methodology}

The current section addresses the research methodology of this paper in form of a research procedure. Furthermore, research questions, artifacts and hypotheses are defined. 


\subsection{Research Approach}

The underlying methodology of this research paper is based on design research [32][33][34]. A design research based process model [35] is chosen (figure 1) to address the research questions. The procedure is separated into six stages. Every single stage is related (in brackets) to the design research approach by Hevner et al. [32] and Takeda et al. [33].

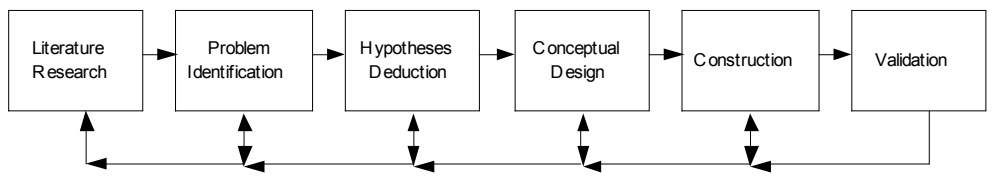

Fig. 1. Research progress related to design research [35]

It starts with the literature research, followed by the problem identification (awareness of a problem). The hypotheses deduction and a first conceptual design (suggestions) are part of the third and fourth stages. Stage five is about the construction (development) of a specific artifact and the procedure concludes with the evaluation (evaluation) in stage six. The focus in this paper lies on stages four and five.

The literature research (stage 1) and the problem identification (stage 2) are already given by the introduction as well as by the theoretical framework and will not be extended by this article. The research questions are below. Hypotheses (stage 3) are not part of this contribution. The main contribution of this paper is a process model that supports the conceptual design (stage 4) as well as the construction (stage 5), which includes addressing the artifacts mentioned below. The validation (stage 6) of specific artifacts is also not part of this article.

\subsection{Research Questions \& Artifacts}

In order to design a transparent communication process between user and service provider for mobile recommendations a couple of research questions are defined. Based on the literature it is indicated that transparency is a new and relevant topic in recommender system's research, especially in the area of mobile recommendations $[10,11,12]$. The following research questions (RS) are defined:

- (RS1) How can transparency be defined (e.g. characteristics) and realized (e.g. design elements) in a mobile environment by considering its advantages and limitations?

- (RS2) How do we design a communication process between user and service provider that makes mobile recommendations more transparent to users?

- (RS3) How can transparency be integrated in order to refine mobile recommendation processes?

- (RS4) How to operate the model of transparency in real-life applications?

According to the design research approach the following artifacts have to be designed: 
- (A1) By addressing RS1 the concept of transparency for a mobile environment is defined that includes the consideration of questions from a data processing point of view as well as general legal conditions.

- (A2) Answering RS2 and RS3 comprises the systematic and engineering course of action to develop and integrate a software component that enables transparency within mobile recommendations.

- (A3) The prototype based development of a transparent mobile event recommender system documents the applicableness of the artifact instantiation in (2).

\subsection{Process Model}

The designed process model covers the research questions as well as the artifacts and supports the conceptual design (stage 4, section 3.1) as well as the construction (stage 5, section 3.2) of transparent mobile recommendations. This section contains a briefly overview while chapter 4-7 is given more detailed information.

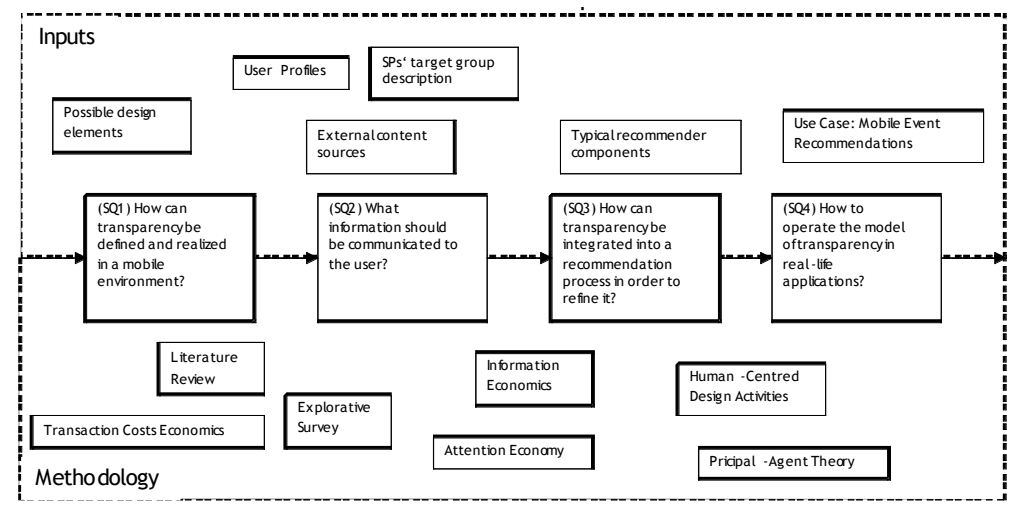

Fig. 2. Process model for how to conduct research of transparent mobile recommendations

The process model is separated into three different sections. First, the input vectors, second, the methodology and third, the four different questions that have to be addressed when you are trying to establish transparency in recommender systems.

Input vectors are information that are used to answer one of the four questions. The different methodologies approaches are used to provide a scientific basis by already well known approaches. The questions that have to be addressed are distinguished into four aspects. The first one discuses how information should be presented, the second what kind of information is relevant to the user, the third addressed the integration of transparency in already existing recommender systems and finally the fourth, the construction of a real life application which states its realization.

The following section addresses each question by demonstrating how the question can be answered by using input values as well as different methodology approaches. 


\section{Representation of Transparency (1)}

When you start thinking about how a mobile recommendation can be made transparent from a user's point of view, at first it is important to know what transparency is about (input values).

\begin{tabular}{|l|l|}
\hline $\begin{array}{l}\text { Enable to make a more } \\
\text { accurate judgment of the true } \\
\text { quality of an item }\end{array}$ \\
\hline $\begin{array}{l}\text { Mechanism for recommen - } \\
\text { dation error handling }\end{array}$ \\
\hline $\begin{array}{l}\text { Explains the user why a } \\
\text { recommendation was made }\end{array}$ \\
\hline $\begin{array}{l}\text { Explains how a system works } \\
\text { information and processes }\end{array}$ \\
\hline $\begin{array}{l}\text { Gives access to information a } \\
\text { firm has collected and how } \\
\text { that information is going to be } \\
\text { used }\end{array}$ \\
\hline
\end{tabular}

Fig. 3. How is transparency defined?

Figure 3 illustrates how transparency can be defined, separated into characteristics and functions. Most of the characteristics are self-explanatory as visible [36], understandable [37], self-explanatory [12,38], interactive [13], transparent [39,40], traceable [41], controllable [42] or penetrable [43,44]. The functions which transparency enables or supports are allowing to make a more accurate judgment of the true quality of a recommended item [16], mechanisms for error handling [11], explanations why a particularly recommendation is made $[12,13,30]$, explanations on how the systems works $[14,15,45]$, provisioning of information and processes [30] and insights into information that a firm stored about a user [46].

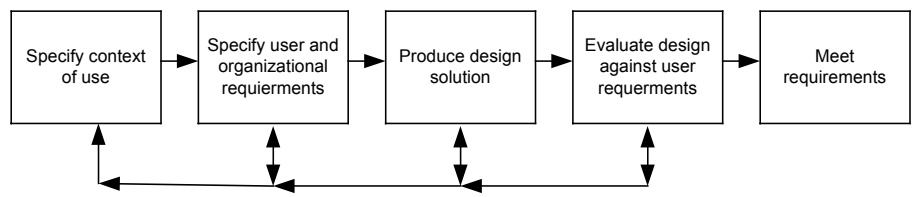

Fig. 4. Human-Centred Design Activities [47]

After knowing what transparency is about, the development of a user interface that offers transparent mobile recommendation is part of the ongoing research. The Human-Centred Design Activities (methodology) procedure given by figure 4, illustrates a guideline on how to design a mobile user interface. After specifying the context of use, requirements as e.g. the functions and the characteristics of a transparent mobile recommendation are specified. Based on these requirements a few different design solutions distinguished by e.g. using different style element as text, video, audio, images or changing the amount of displayed information e.g. only 3 explanations for each recommendation or 4 or 5 , are developed and evaluated by using e.g. user trials in order to check if the initial requirements are meet. The result should be a user interface that allows the representation of transparent mobile recommendations. 


\section{Information Relevance (2)}

After the investigation of how transparency is defined and how to represent transparent mobile recommendations in chapter 4 , it is also important to know what kind of information is relevant from the user's point of view. First, the information that can be used (input values) to be visualized is separated into available information and relevant information.

The available information is e.g. the service provider target group description which can include for instance age, gender, professionalism, occupation group, income, basic setting, interests, work attitude, personality, country, region, location, frequency of use or brand loyalty [48]. In addition there is user generated information as part of the available information as e.g. information that is stored in user profiles [35]. Such information can be a pseudonym, age, interest or other. Direct user feedback by for instance explicit answering of questions as "was the recommendation helpful?", indirect user feedback by deriving the user's behavior through surf behavior, mouse movements, scroll behavior, retention period or iris movements [27] and information of a user as e.g. location information provided by a third party, completes the picture of the available information.

Relevant information is typically the kind of information the user concerns about most. By looking into the already established research approaches (methodology) three different theories can help to answer this question. First the attention economy $[1,2]$ which is based on the limited attention of a user. The high amount of available information cannot be searched by humans because their capacity is limited. Therefore it is important the offer the user a set of information that is probably interesting for him by filtering out irrelevant information. The transaction costs theory [49] also supports the question about the information relevance from a user's perspective. Looking for information takes time which produces costs. Finding relevant information is a less time consuming step and will reduce search costs. The third theory is about risk and uncertain [50]. An Information that is provided for instance by a recommender engine has to be trustful. The user should have the possibility to check if the recommendation is right.

Trying to find a match between the service provider target group description and the user profile attributes involves a matching process which can be typically described by figure 5 .

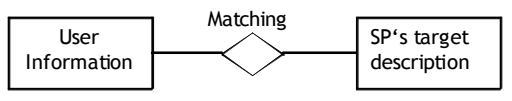

Fig. 5. Matching Process

The classical matching can be done rule-based as given below:

IF

user_profile_attribute ${ }_{i 1}\left(\mathrm{UPA}_{\mathrm{i} 1}\right)=$ service_provider_attribute $\mathrm{j}_{\mathrm{j} 1}\left(\mathrm{SPA}_{\mathrm{j} 1}\right)$ AND/OR IF

user_profile_attribute $\mathrm{i}_{\mathrm{i} 2}\left(\mathrm{UPA}_{\mathrm{i} 2}\right)=$ service_provider_attribute $\mathrm{j}_{\mathrm{j} 2}\left(\mathrm{SPA}_{\mathrm{j} 2}\right)$ AND/OR IF

user_profile_attribute $e_{i n}\left(\mathrm{UPA}_{\text {in }}\right)=$ service_provider_attribute ${ }_{j \mathrm{jm}}\left(\mathrm{SPA}_{\mathrm{jm}}\right)$

THEN match

ELSE no match 
Due to the fact that each user attribute has its specific relevance, each attribute needs to have a weight which expresses the relevance. A user profile $\left(U_{\mathrm{i}}\right)$ consists of several user attribute (UPA). UP $\mathrm{i}_{\mathrm{i}}=\left\{\mathrm{UPA}_{\mathrm{i}}, \ldots \mathrm{UPA}_{\mathrm{in}}\right\}$. Each attribute has a name $\left(U_{P A N}\right)$ and a weight $\left(U P A W_{i}\right)$ which indicates its importance to the user. $U A_{i}=$ $\left\{\left(\mathrm{UPAN}_{\mathrm{i} 1}, \mathrm{UPAW}_{\mathrm{i} 1}\right), \ldots,\left(\mathrm{UPAN}_{\mathrm{in}}, \mathrm{UPAW}_{\mathrm{in}}\right)\right\}$.

The main question that has to be answered by individual research is what factors have an impact on user's relevance in a specific application area. UPAW $\mathrm{U}_{i}=\left\{\mathrm{A}_{\mathrm{i}}+\mathrm{B}_{\mathrm{i}}\right.$ $\left.+\mathrm{C}_{\mathrm{i}}+\mathrm{D}_{\mathrm{i}}+\mathrm{E}_{\mathrm{i}}+\ldots.\right\}$

\section{Integration of Transparency (3)}

The question of the integration of transparency has to investigate the structure of traditional recommender systems. The following structure of a recommender system is derived by literature research.

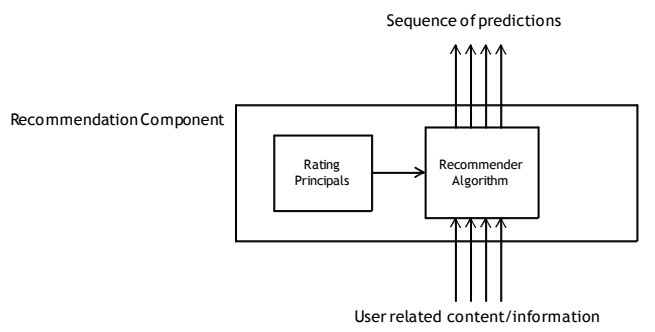

Fig. 6. Classical Recommender System

A classical recommender system always consists of user related information as input, a recommendation algorithm, rating principals the algorithm is operating on and a sequence of predictions as output [51]. In order to offer transparency within recommendations, the following enhancements are proposed.

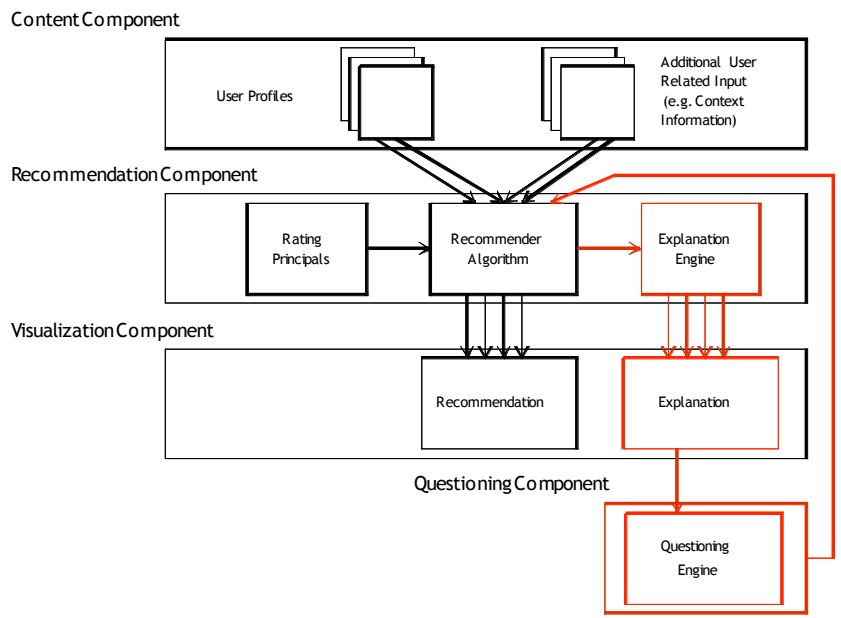

Fig. 7. Transparency in classical recommender systems 
The proposed architecture comprises three additional components: the explanation engine, the explanation and the questioning engine. The explanation engine is located within the recommendation component. After the recommender algorithm generated the recommendation, information about the system conclusion is transferred to the explanation engine which main task is the processing for the explanation. The component called explanation which is located in the visualization component is responsible for the visualization of the underlying conclusion. The visualization can be performed by e.g. different style elements as mentioned at the end of section 4 . The questioning engine allows to critique the system assumption for a particularly recommendation. Remember that transparency should help the user to understand why a particularly recommendation was made, especially in the case of a wrong recommendation.

By offering transparency new direct user feedback is generated that can be used to refine existing recommendations.

\section{Real-Life Application Scenario (4)}

The last part of the process model, described in section 3, is the development of a real life application that is operating on the previously findings. The application that is chosen is a transparent mobile event recommender system, called MoReCa.

Events are typically every kind of activity users can participate in, e.g. movies, concerts, lectures, meetings, dinners and others. An event is minimally described by its name, a location where it takes place and a time when it starts and ends. Why an event is recommended to a user can have several reasons. An event can be recommended based on user's interests, on the distance between the event's location and the user's current position, due to the fact that a couple of friends already accepted the recommendation or the user's calendar is just empty. The event, in this case the movie "Spiderman 4", is described by its name, the location, the date and the time. By asking the system why this recommendation is made, MoReCa will display explanations for the recommendation, given by figure 8 .

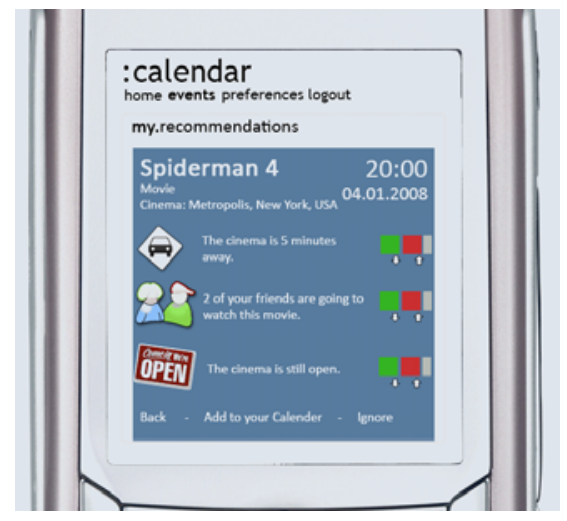

Fig. 8. Transparency in mobile event recommendations 
An explanation, in this example, consists of a icon and textual description and enables the possible to give explicit feedback in the form of yes the explanation is right, no it is wrong, it is inappropriate for this recommendation or by changing the order to express the relevance of an explanation.

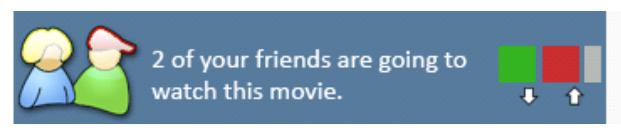

Fig. 8. Transparent explanation of a mobile event recommendation

This representation of transparent recommendations can allow being more tolerant against wrong recommendations and providing active user feedback to refine recommendations.

\section{Conclusion and Outlook}

The paper in hand discussed the important and relevance of transparency in mobile recommendations in order to establish a more human like recommendation process. When it comes to a mobile environment transparency is completely new, especially its visualization and integration into mobile recommender systems. Furthermore the article offered a procedure that demonstrates how research of transparency for mobile recommendations can be conducted.

Based on this procedure the development of a real life application, a transparency mobile event recommender system, is an ongoing development, which will be evaluated at the end of 2008 .

According the research approach in section 3.1, the work this paper presented has covered the fourth and fifth stages.

\section{References}

1. J.K. Bleicher and K. Hickethier, Aufmerksamkeit, Medien und Ökonomie. Lit, 2002.

2. G. Franck, Ökonomie der Aufmerksamkeit. Carl Hanser, 1998.

3. P. Zipkin, The limits of mass customization, Sloan Management Review 42,3, 2001, pp. 8187.

4. Q.N. Nguyen and F. Ricci, User Preferences Initialization and Integration in Critique-Based Mobile Recommender Systems, AIMS, Nottingham, UK, 2004.

5. J.A. Konstan, B.N. Miller, D. Maltz, J.L. Herlocker, R. Gordon, E. Prairie and J. Riedl, GroupLens: applying collaborative filtering to Usenet news, Communications of the ACM, Vol.40, No.3, 1997, pp. $77-87$.

6. B.J. Dahlen, J.A. Konstan, J.L. Herlocker, N. Good, A. Borchers and J. Riedl. Jump- starting movielens: User benefits of starting a collaborative filtering system with "dead data", University of Minnesota TR 98-017, 1998.

7. W.C. Hill, L. Stead, M. Rosenstein and G.W. Furnas: Recommending and Evaluating Choices in a Virtual Community of Use, CHI 1995, pp. 194-201. 
8. U. Shardanand and P. Maes, Social Information Filtering: Algorithms for Automating "Word of Mouth", Conference on Human Factors in Computing Systems, 1995.

9. M. Balabanović and Y. Shoham, Fab: content-based, collaborative recommendation. Communications of the ACM, Vol.40, No.3, 1997, pp. 66-73.

10. M. Hingston, User Firendly Recommender Systems, University of Sydney, School of Information Technologies, 2006.

11. J.L. Herlocker, J.A. Konstan and J. Riedl, Explaining collaborative filtering recommendations, ACM conference on CSCW, 2001, pp. $241-250$.

12. R. Sinha, and K. Swearingen, The role of transparency in recommender systems, Conference on Human Factors in Computing Systems, Minneapolis, Minnesota, USA, 2002, pp. 830-831.

13. N. Tintarev and J. Masthoff, A Survey of Explanations in Recommender Systems, Workshop on Recommender Systems and Intelligent User Interfaces associated with ICDE'07, Instanbul, Turkey, 2007.

14. N. Tintarev, Explanations of Recommendations, ACM Recommender Systems, Minneapolis, Minnesota, USA, 2007, pp. 203-206.

15. J. Muramatsu and W. Pratt, Transparent Queries: investigation users' mental models of search engines, ACM SIGIR conference on research and development in information retrieval, New Orleans, Louisiana, United States, 2001, pp. 217 - 224.

16. M. Bilgic R.J. Mooney, Explaining Recommendations: Satisfaction vs. Promotion, Beyond Personalization 2005: A Workshop at the International Conference on Intelligent User Interfaces, San Diego, CA, 2005.

17. S. Figge, Innovatives Mobile Marketing - Kontextabhängige Kundenansprache mit Hilfe mobiler Portale, in Rannenberg, Kai (Hrsg.): Schriften zum Mobile Commerce und zur Mobilkommunikation; Hamburg 2006.

18. A. Albers, An Electronic Market Framework for context-sensitive Mobile Consumer Profiles in the Marketing Domain, AMCIS, Keystone, USA August 2007.

19. M. Radmacher, J. Zibuschka, T. Scherner, L. Fritsch and K. Rannenberg, Privatsphärenfreundliche topozentrische Dienste unter Berücksichtigung rechtlicher, technischer und wirtschaftlicher Restriktionen, WI, Karlsruhe, 2007.

20. J. Zibuschka, L. Fritsch, M. Radmacher, T. Scherner and K. Rannenberg, Privacy-Friendly LBS: A Prototype-supported Case Study, AMCIS, Keystone, USA August 2007.

21. P. Resnick and H.R. Varian, Recommender Systems, Communications of the ACM, Vol.40, No.3, 1997, pp.56-58.

22. R. van Meteren and M. van Someren, Using Content-Based Filtering for Recommendation, University of Amsterdam, Netherlands, 2000.

23. H. Eui-Hong and G. Karypis: Feature-based recommendation system. CIKM 2005, pp. 446452.

24. B. Sarwar, G. Karypis, J. Konstan and J. Riedl, Item-based collaborative filtering recommendation algorithms, $10^{\text {th }}$ international conference on WWW, 2001, pp. 285-295.

25. J. Donaldson, A Hybrid Social-Acoustic Recommendation System for Popular Music, ACM Recommender Systems, Minneapolis, Minnesota, USA, 2007, pp. 187-190.

26. L.M. Quiroga and M. Mostafa, An experiment in building profiles in information filtering: the role of context of user relevance feedback, Information Processing and Management Vol.38, No.5, 2002.

27. X. Fu, Evaluating Sources of Implicit Feedback in Web Search. ACM Recommender Systems, Minneapolis, Minnesota, USA, 2007, pp. 191-194.

28. S. Jung, J.L. Herlocker and J.Webster, Click data as implicit relevance feedback in web search, Inf. Process. Manage. Vol.43, No.3, 2007, pp. 791-807.

29. P. Pu, User-Involved Preference Elicitation, IJCAI Workshop on Configuration, Gentilly Cedex, France, 2003. 
30. K. Swearingen and R. Sinha, Beyond Algorithms: An HCI Perspective on Recommender Systems. SIGIR workshop on Recommender Systems, New Orleans, LA, USA, 2001.

31. M. Radmacher, Elicitation of profile attributes by transparent communication, ACM Recommender Systems, Minneapolis, Minnesota, USA, 2007, pp. 199-202.

32. A.R. Hevner, et.al., Design Science Information Systems Research, MIS Quarterly, Vol.28, No.1, 2004, pp. 75-105.

33. H. Takeda, et. al., Modeling Design Processes, AI Magazine, 1990, pp. 37-48.

34. V. Vaishnavi and B. Kuechler, Design Research in Information Systems, AIS, 2006.

35. M. Radmacher, Adaptive Customer Profiles For Context Aware Services in a Mobile Environment, In IFIP International Federation for Information Processing, Volume 251, Integration and Innovation Orient to E-Society Volume 1, Wang, W. (Eds), (Boston: Springer), pp. 390-399; Wuhan, China.

36. J. Koenemann and N. Belkin, A case for interaction: A study of interactive information retrieval behavior and effectiveness, in Proceedings of the Human Factors in Computing Systems Conference, NY, 1991.

37. S. Maßß, Transparenz. Eine zentrale software-ergonomische Forderung, Report Nr. FBIHH-B-170/94, Hamburg, 1994.

38. J. Wandmacher, Software-Ergonomie, de Gruyter, Berlin, 1993.

39. S. Bødker, Through the Interface- a Human Activity Approach to User, Interface Design, Dissertation, Aarhus University 1987.

40. D.A., Norman, The Invisible Computer: Why Good Products Can Fail, the Personal Computer is So Complex, and Information Appliances Are the Solution. Cambridge, MIT Press, 1998.

41. M. Fritter, Towards More "Natural" Interactive Systems, International Journal of ManMachine Studies, 11, 1979, pp. 339-350.

42. M. Frese, A Theory of Control and Complexity: Implications for Software-Design and Integration of Computer Systems into the Work Place, in: M. Frese, E. Ulich, W. Dzida (Hrsg.), Psychological Issues of HCI in the Work Place. Elsevier Science, Amsterdam, 1987, pp. 313-337.

43. P. Spinas, N. Troy, E. Ulich, Leitfaden zur Einführung und Gestaltung von Arbeit mit Bildschirmsystemen, München, 1983.

44. H. Oberquelle. Situationsbedingte und benutzerorientierte Anpaßbarkeit von Groupware, in A. Hartmann, T. Herrmann, M. Rohde, V. Wulf (Hrsg.), Menschengerechte Groupware Software-ergonomische Gestaltung und partizipative Umsetzung, Chapter of the ACM, 42, Teubner, Stuttgart, 1994, S. 31-49.

45. S. Maaß, Why Systems Transparency?, in T. R.G. Green, S. J. Payne, G. C. van der Veer (Hrsg.). The Psychology of Computer Use. Academic Press, London, 1983, pp.19-28.

46. N.F. Awad and M.S. Krishnan, The Personalization Privacy Paradox: An Empirical Evaluation Of Information Transparency and the Willingness to be Profiled Online for Personalization, MIS Quarterly, Vol.30, No. 1, 2006, pp.13-28.

47. S. Love, Understanding Mobile Human-Computer Interaction, Butterworth Heinemann, Great Britain, 2005.

48. P. Kotler, and F. Bliemel, Marketing-Management, Schaeffer-Poeschel, Auflage10., überarb. und aktualisierte Aufl, Stuttgart, ISBN: 9783791016894, 2001.

49. O. L. Williamson, Organization Theory: From Chester Barnard to the Present and Beyond, Oxford University Press US, ISBN 0195098307, 1985.

50. T. Ripperger, Ökonomik des Vertrauens - Analyse eines Organisationsprinzips, Mohr Siebeck Verlag Tübingen 1998.

51. P. Resnick and R. Sami, The Influence Limiter: Provably Manipulation-Resistant Recommender Systems, ACM Recommender Systems, Minneapolis, Minnesota, USA, 2007, pp. 17-24. 